\title{
Portal-hepatic Venous Shunt through a Portal Aneurysm Complicated by Hepatic Encephalopathy and Pulmonary Hypertension
}

\author{
Tatsuya Hondo, Hiroki Teragawa, Makoto Munemori, Nobuyuki Morishima, Hiroshi Watanabe, \\ Satoshi Ogata, Hirotoki Ohe, Motohiro Yoshikawa and Makoto Ohbayashi
}

\begin{abstract}
We report a rare case of portal-hepatic venous shunt through an enormous portal aneurysm complicated by pulmonary hypertension. A 66-year-old woman was admitted to our hospital for hepatic encephalopathy. Chest roentgenography revealed pulmonary hypertension. Computed tomography and ultrasound examination demonstrated a shunt between the portal and hepatic veins through an enormous portal aneurysm. The diagnoses of portal-hepatic venous shunt and pulmonary hypertension were confirmed by hepatic venous catheterization and cardiac catheterization. Pulmonary hypertension might result from the effects of vasoconstrictive agents, which should be metabolized by the liver in normal subjects, passing through the intrahepatic shunt into the lung.
\end{abstract}

(Internal Medicine 36: 790-793, 1997)

Key words: intrahepatic shunt, liver cirrhosis

\section{Introduction}

Various types of portal-systemic collaterals are known to occur in patients with portal hypertension. Recently, some cases of intrahepatic shunt between the portal and hepatic veins have been reported (1-15). However, pulmonary hypertension associated with enormous intrahepatic shunt is rare (13). In this report, we describe a case of portal-hepatic venous shunt through an enormous portal aneurysm complicated by hepatic encephalopathy and pulmonary hypertension.

\section{Case Report}

A 66-year-old woman was admitted to our hospital on January 8, 1996, because of disturbance of consciousness. Eight years before admission, diagnoses of liver cirrhosis and Sjögren's syndrome were made. Six years before admission, the patient complained of dyspnea, and a chest roentgenogram revealed pulmonary hypertension. On the day of admission, the patient was found lying unconscious at her house and was brought to our hospital by ambulance.

On admission, her blood pressure was $130 / 70 \mathrm{mmHg}$ and her pulse was regular at 70 per minute. The patient was confused and could not give relevant answers to simple questions about place and time. Her face was edematous. Flapping tremor was observed in her outstretched hands. Breath sounds were normal, and there were no rales. The second heart sound was accentuated in the pulmonic valve area. The abdomen was flat and the liver was not palpable. Laboratory examination disclosed white blood cell count, $3,400 / \mathrm{mm}^{3}$; red blood cell count, $447 \times 10^{4} / \mathrm{mm}^{3}$; hemoglobin, $13.7 \mathrm{~g} / \mathrm{dl}$; platelet count, $11.6 \times 10^{4} /$ $\mathrm{mm}^{3}$; total bilirubin, $1.51 \mathrm{mg} / \mathrm{dl}$; aspartate aminotransferase, $48 \mathrm{IU} / l$; alanine aminotransferase, $21 \mathrm{IU} / l$; albumin, $3.3 \mathrm{~g} / \mathrm{dl}$; A/ $\mathrm{G}, 0.69 ; \mathrm{NH}_{3}, 136 \mu \mathrm{g} / \mathrm{dl} ; \mathrm{ICG}$ (15 minutes), $45.5 \%$; and positive hepatitis $\mathrm{C}$ antibody (Table 1).

A chest roentgenogram revealed enlarged main branches of the pulmonary artery, indicating pulmonary hypertension (Fig. 1), but echocardiography with Doppler technique revealed no cardiac disease which caused secondary pulmonary hypertension. Abdominal computed tomography showed splenomegaly, dilated intrahepatic portal vein and a portal aneurysm (Fig. 2). Ultrasound examination also revealed the aneurysm, which was connected with the left portal branch and the left hepatic vein. Endoscopy revealed no esophageal varices.

Postarteriographic portography revealed large pooling of the contrast medium in the aneurysm with connection to the left

From the Department of Internal Medicine, Onomichi General Hospital, Onomichi Received for publication January 16, 1997; Accepted for publication July 10, 1997

Reprint requests should be addressed to Dr. Tatsuya Hondo, the Department of Internal Medicine, Onomichi General Hospital, 7-19 Kohama-cho, Onomichi, Hiroshima 722 
Portal-hepatic Venous Shunt

Table 1. Laboratory Data on Admission

\begin{tabular}{lrlr}
\hline White blood cell & $3,400 / \mu \mathrm{l}$ & Serum electrophoresis (\%) & \\
Red blood cell & $447 \times 10^{4} / \mu \mathrm{l}$ & Albumin & 41.3 \\
Hemoglobin & $13.7 \mathrm{~g} / \mathrm{dl}$ & $\alpha_{1}$ & 1.7 \\
Platelet & $11.6 \times 10^{4} / \mu \mathrm{l}$ & $\alpha_{2}$ & 4.8 \\
Total bilirubin & $1.51 \mathrm{mg} / \mathrm{dl}$ & $\beta$ & 9.3 \\
Zinc sulfate turbidity test & $25.8 \mathrm{KU}$ & $\gamma$ & 42.9 \\
Aspartate aminotransferase & $48 \mathrm{IU} / l$ & IgG & $2,850 \mathrm{mg} / \mathrm{dl}$ \\
Alanine aminotransferase & $21 \mathrm{IU} / l$ & IgA & $817 \mathrm{mg} / \mathrm{dl}$ \\
$\gamma$-glutamyltranspeptidase & $13 \mathrm{IU} / l$ & IgM & $206 \mathrm{mg} / \mathrm{dl}$ \\
Lactate dehydrogenase & $557 \mathrm{IU} / l$ & Anti-nuclear antibody & $\times 80$ \\
Cholinesterase & $2,497 \mathrm{IU} / l$ & Anti-SS-A antibody & $256>$ \\
Total protein & $8.1 \mathrm{~g} / \mathrm{dl}$ & Anti-SS-B antibody & negative \\
Albumin & $3.3 \mathrm{~g} / \mathrm{dl}$ & CH50 & $28.4 \mathrm{U} / \mathrm{ml}$ \\
Albumin/Globulin ratio & 0.69 & Amino acid (nmol/ml) & \\
Urea nitrogen & $13.1 \mathrm{mg} / \mathrm{dl}$ & Valine & 133.0 \\
Creatinine & $0.3 \mathrm{mg} / \mathrm{dl}$ & Leucine & 72.6 \\
Na & $141 \mathrm{mEq} / l$ & Isoleucine & 42.5 \\
$\mathrm{~K}$ & $3.6 \mathrm{mEq} / l$ & Tyrosine & 134.2 \\
Cl & $102 \mathrm{mEq} / l$ & Phenylalanine & 81.8 \\
$\mathrm{NH} 3$ & $136 \mu \mathrm{g} / \mathrm{dl}$ & Fisher ratio & 1.1 \\
Indocyanine green test $(15 \mathrm{~min})$ & $45.5 \%$ & Hepatitis B surface antigen & $(-)$ \\
& & anti-hepatitis C virus antibody & $(2+)$ \\
\hline
\end{tabular}

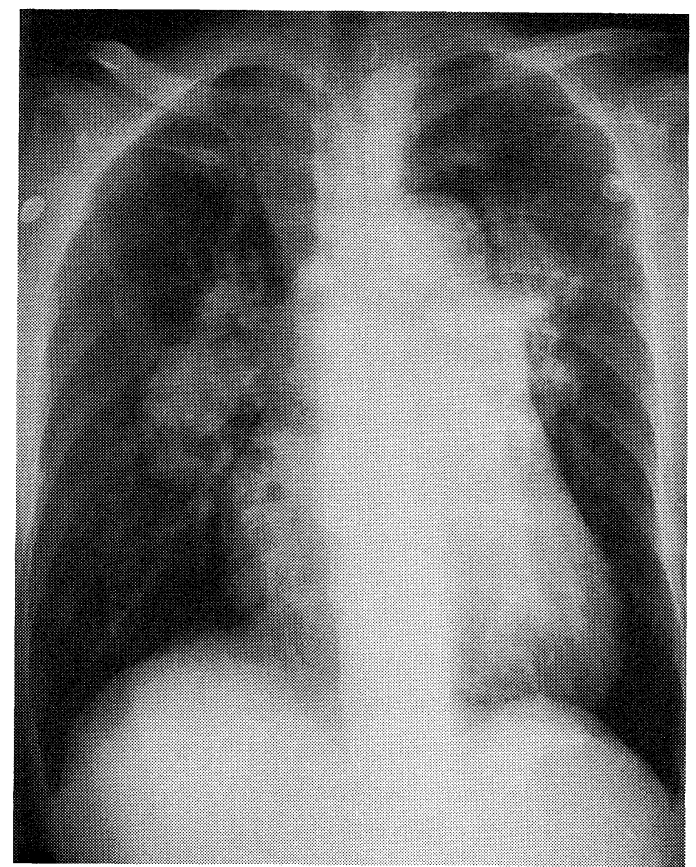

Figure 1. Chest roentgenogram on admission reveals marked dilatation of pulmonary main branches.

hepatic vein (Fig. 3). Hepatic venous catheterization and right cardiac catheterization were also performed. Balloon occlusive left hepatic venography clearly and antidromically demonstrated this abnormal communication (Fig. 3). The mean wedged hepatic venous pressure was $12 \mathrm{mmHg}$, mean right atrial

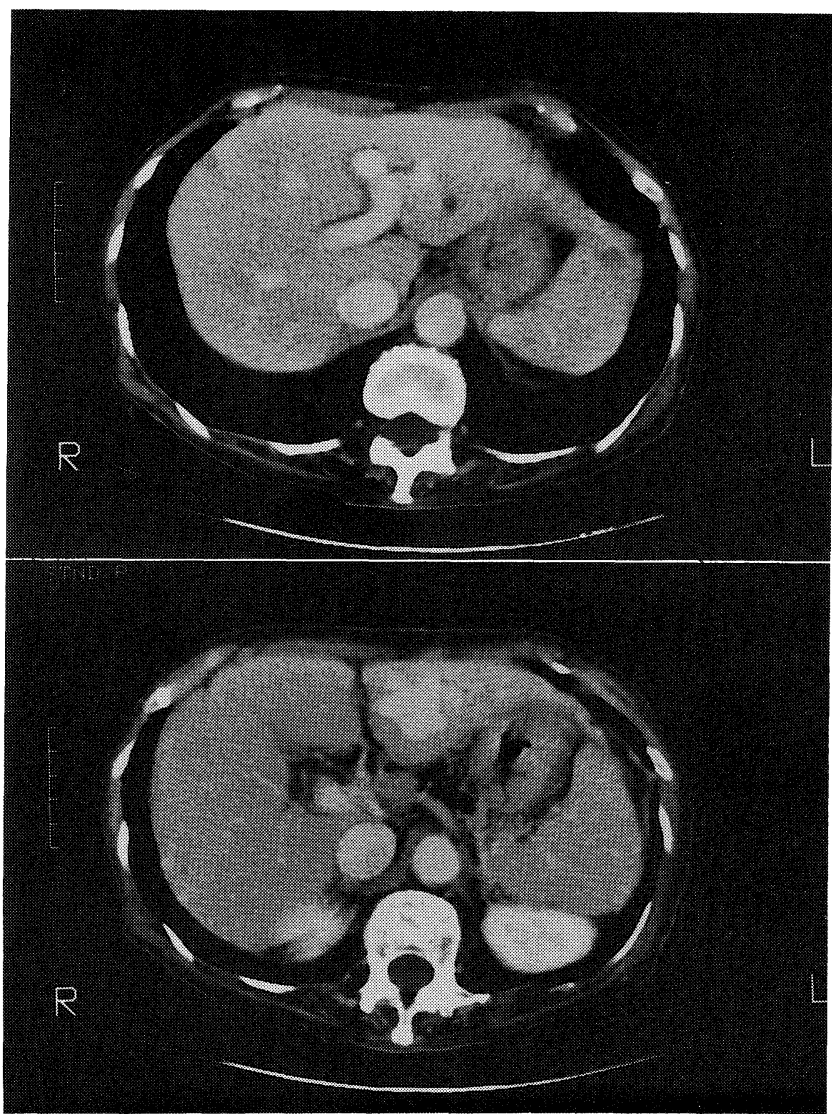

Figure 2. Computed tomography demonstrates a dilated intrahepatic portal vein (upper panel) and a portal aneurysm (lower panel). 
pressure $3 \mathrm{mmHg}$, right ventricular pressure 60/1 $\mathrm{mmHg}$, pulmonary artery pressure $60 / 24 \mathrm{mmHg}$ and cardiac output 5.1 $l /$ min. Marked decrease in pulmonary artery pressure was not observed during the 10-minute occlusion of the shunt by a
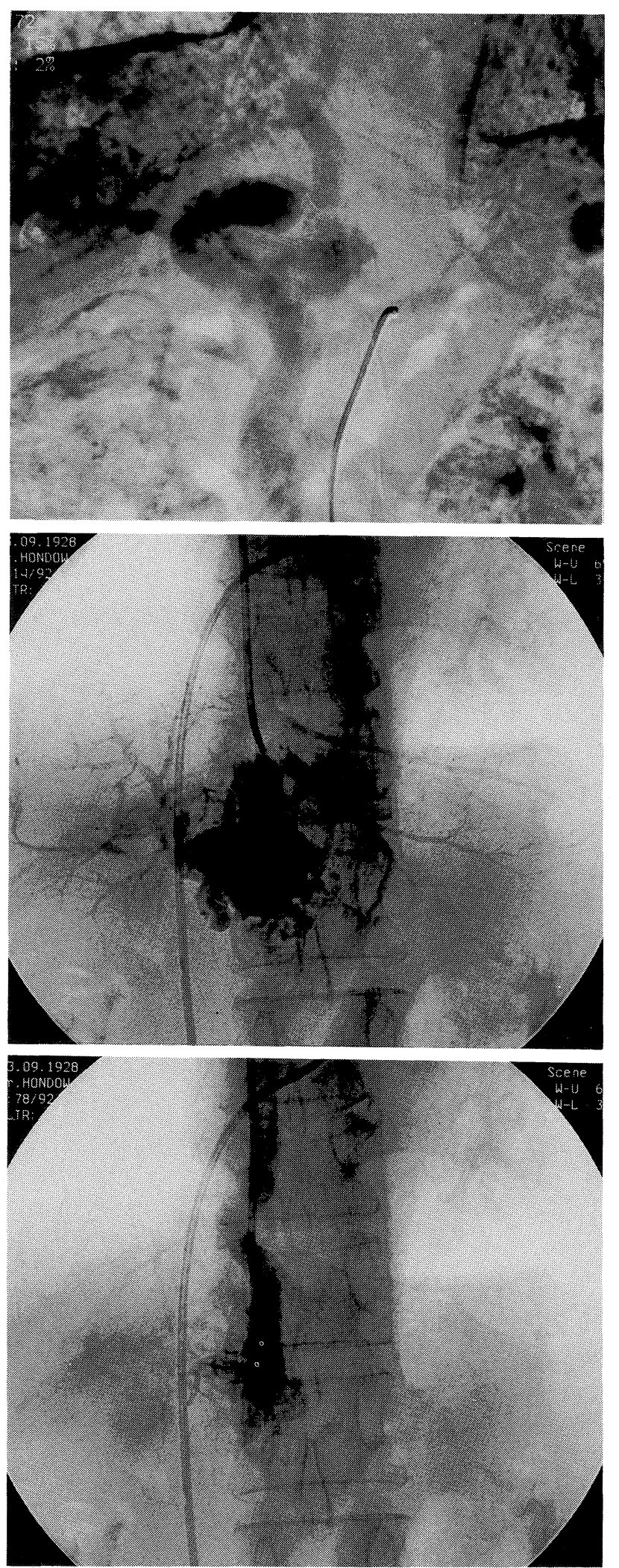

balloon catheter.

Embolization of the shunt using a coil was not performed because the portal aneurysm was so enormous that there was a high probability of dislodgement of a coil or pulmonary embolism, and because pulmonary hypertension had not markedly improved during the balloon obstruction test. She improved with conventional treatment for hepatic encephalopathy and was discharged from our hospital on May 21, 1996.

\section{Discussion}

Although esophageal varices, splenorenal venous shunts and other are well known as portal-systemic venous shunts in patients with portal hypertension, shunts within the hepatic parenchyma are rare. Park et al (1) reviewed fourteen cases and classified them into four types. The first type is a single large tube that connects the right portal vein to the inferior vena cava; the second is a localized peripheral shunt; the third is an aneurysm that connects the portal and hepatic veins; and the fourth involves multiple communications diffusely in both lobes.

The cause of portal-hepatic venous shunt remains unclear. Raskin et al (2) reported a case with a large number of shunts between the portal and hepatic veins, which was classified as the fourth type of Park et al (1), and they considered persistence of portions of the omphalomesenteric venous system to be the most likely explanation for this anomaly. Kozuka et al (3) reported an autopsy case, classified as the first type by Park et al (1), and considered that the shunt might not be a congenital malformation but a vascular disorder resulting from the parenchymal collapse of the liver following massive necrosis.

The portal-hepatic venous shunt through an aneurysm in our case was of the third type in Park's classification (4-12). Portal aneurysms (without intrahepatic shunt) have been also reported $(16,17)$, and it has been thought that it might be congenital or secondary to portal hypertension. In the case of portal aneurysm with portal-hepatic venous shunt, two theories as to the cause have also been offered. Takayasu et al (4) considered that a portal aneurysm, which was the result of portal hypertension, ruptured into the hepatic vein. Chagnon et al (5) considered that portal aneurysm and portal-hepatic venous shunt were both congenital. In the present case, the patient had liver cirrhosis with portal hypertension, but there has been no sudden episode indicating rupture of a portal aneurysm.

Pulmonary hypertension was present in our case. It has been pointed out that there is some relation between pulmonary

Figure 3. Postarteriographic portogram shows large pooling of contrast medium in the aneurysm (upper panel). Two catheters are inserted (middle and lower panel); one is from the femoral vein to the pulmonary artery and the other is from the right subclavian vein to the left hepatic vein. Balloon occlusive left hepatic venogram demonstrated the aneurysm (middle panel). When the balloon was deflated, a flow of contrast medium into the right atrium was observed (lower panel). 
hypertension and portal hypertension because the prevalence of pulmonary hypertension among patients with portal hypertension is much higher than that of primary pulmonary hypertension in the general population (18).

The etiology of pulmonary hypertension in association with portal hypertension is controversial, and various hypotheses have been proposed. Naeye (19) found that emboli or thrombi were widespread throughout the small pulmonary arteries and that thrombi were present in the portal venous system in their cases, and he attributed pulmonary hypertension to recurrent pulmonary embolization. Chun et al (20) considered that pulmonary hypertension might result from the increased circulating blood volume due to liver cirrhosis. Lebrec et al (18) considered that inflow of vasoconstrictive agents or substances toxic to the wall of the small pulmonary arteries, which are destroyed by the liver in normal subjects, might cause pulmonary hypertension. Autoimmune phenomena have also been considered as possible causes of pulmonary hypertension (21).

In this case, there had been no clear episode of pulmonary embolism and there was no clear shadow of thrombus in the portal aneurysm. It seemed unlikely that the patient's pulmonary hypertension was caused by expanded total blood volume because there was no increase in cardiac output. Sjögren's syndrome was also present in this case, but pulmonary hypertension is rare in patients with this syndrome (22).

In previous reports, it has been pointed out that the prevalence of pulmonary hypertension was high especially in patients with surgical portal-systemic shunts and spontaneous large shunts $(18,23)$. Hiyama (23) showed experimentally that pulmonary hypertension develops after portal-systemic shunt operations in rats, and the degree of the hemodynamic and pathological changes were related to the shunt ratio. Moreover, from an investigation about vasoactive substances derived from the portal venous system, he suspected that endotoxin passing through the shunt might play an important role in the development of pulmonary hypertension. In our case, it seems natural to suppose that pulmonary hypertension might result from the effects of vasoconstrictive agents passing through the enormous portal-hepatic venous shunt. However, pulmonary hypertension did not markedly improve during balloon obstruction test, suggesting that the pulmonary arterial walls had already changed irreversively due to chronic exposure to the toxic substances.

\section{References}

1) Park JH, Cha SH, Han JK, Han MC. Intrahepatic portosystemic venous shunt. Am J Roentgenol 155: 527, 1990.

2) Raskin NH, Price JB, Fishman RA. Portal-systemic encephalopathy due to congenital intrahepatic shunts. New Engl J Med 270: 225, 1964.

3) Kozuka S, Sassa R, Kakumu S. An enormous intrahepatic shunt between portal vein and hepatic one. Angiology 26: 365, 1975.
4) Takayasu K, Moriyama N, Shima Y, et al. Spontaneous portal-hepatic venous shunt via on intrahepatic portal vein aneurysm. Gastroenterology 86: $945,1984$.

5) Chagnon SF, Vallee CA, Barge J, Chevalier LJ, Le Gal J, Blery MV. Aneurysmal Portahepatic venous Fistula: Report of two cases. Radiology 159: 693, 1986.

6) Tanaka S, Kitamura T, Fujita M, et al. Intrahepatic venous and portal venous aneurysms examined by color Doppler flow imaging. J Clin Ultrasound 20: 89, 1992.

7) Tsukuda M, Yokomizo Y, Nanbu T, Tamura S. Intrahepatic portal vein aneurysm with portal-hepatic venous shunt: Case report. Nippon Igaku Hoshasen Gakkai Zasshi 48: 304, 1988 (Abstract in English).

8) Horiguchi $Y$, Kitano $T$, Imai H, Ohsuki M, Yamaguchi M, Ito M. Intrahepatic portal-systemic shunt: Its etiology and diagnosis. Gastroenterol Jpn 22: 496, 1987.

9) Shinagawa T, Iino Y, Ukaji H, Ishizuka M. Intrahepatic portal-hepatic venous shunt diagnosed by ultrasound and computed tomography. Kanzo (Acta Hepatologica Japonica) 27: 242, 1986 (Abstract in English).

10) Wittich G, Jantsch H, Tscholakoff D. Congenital portosystemic shunt diagnosed by combined real-time and Doppler sonography. J Ultrasound Med 4: 315, 1985.

11) Kitami $Y$, Usui $Y$, Rai F, Tominaga $S$, Hashino H. A surgical case of portal systemic encephalopathy due to an enormous port-hepatic venous shunt. Nippon Rinsho Geka Igakkai Zasshi (J Jpn Soc Clin Surg) 46: 1000, 1985 (Abstract in English).

12) Horiguchi $\mathrm{Y}$, Kitano $\mathrm{T}$, Taguchi $\mathrm{H}$, et al. Two cases of intrahepatic portasystemic shunt. Kanzo (Acta Hepatologica Japonica) 25: 794, 1984 (Abstract in English).

13) Nakatsuji $Y$, Kiyosawa K, Furuta K, et al. A case of hepatic encephalopathy and pulmonary hypertension due to intrahepatic portacaval shunt. Kanzo (Acta Hepatologica Japonica) 32: 197, 1991 (Abstract in English).

14) Ohnishi K, Saito M, Saito M, Terabayashi H, Okuda K. Hepatic encephalopathy associated with extensive portal-hepatic venous shunts: A case report. Am J Gastroenterol 80: 60, 1985.

15) Tsujimoto T, Fukui K, Matsumura M, et al. A case of idiopathic portal hypertension with large intrahepatic portal-hepatic venous shunts. Kanzo (Acta Hepatologica Japonica) 37: 440, 1996 (Abstract in English).

16) Ohnishi $K$, Nakayama $T$, Saito $M$, et al. Aneurysm of the intrahepatic branch of the portal vein. Report of two cases. Gastroenterology 86: 169, 1984.

17) Sato $T$, Kawakatsu M, Igarashi $Y$, et al. A case report of intrahepatic portal vein aneurysm; Diagnostic usefulness of MRI. Rinsho Hoshasen (Jpn J Clin Radiol) 34: 277, 1989 (Abstract in English).

18) Lebrec D, Capron JP, Dhumeaux D, Benhamou JP. Pulmonary hypertension complicating portal hypertension. Am Rev Respir Dis 120: 849, 1979.

19) Naeye RL. "Primary" pulmonary hypertension with coexisting portal hypertension. A retrospective study of six cases. Circulation 22: 376, 1960.

20) Chun PKC, Antonio RPS, Davia JE. Laennec's cirrhosis and primary pulmonary hypertension. Am Heart J 99: 779, 1980.

21) Morrison EB, Gaffney FA, Eigenbrodt EH, Reynolds RC, Buja LM. Severe pulmonary hypertension associated with macronodular (postnecrotic) cirrhosis and autoimmune phenomena. Am J Med 69: 513, 1980.

22) Kishida Y, Hosoda Y. Pulmonary vascular changes in the collagen vascular diseases. Kokyu to Junkan 39: 952, 1991 (in Japanese).

23) Hiyama E. Pulmonary vascular changes after portasystemic shunt operation in rats. Nippon Geka Gakkai Zasshi (J Jpn Surg Soc) 90: 874, 1989 (Abstract in English). 